$\mathbb{T}$ periodica polytechnica

Mechanical Engineering

$54 / 2$ (2010) 95,97

doi: 10.3311/pp.me.2010-2.06

web: http://www.pp.bme.hu/me

(C) Periodica Polytechnica 2010

RESEARCH ARTICLE

\section{Investigation of heparin binding capacity of polyurethane coatings}

Liza Pelyhe

Received 2010-11-31

\begin{abstract}
In this article the investigation of heparin binding capacity of three biocompatible polyurethane coating are shown. The polyurethanes as coating on metal carrier were studied. The heparin binding capacity has measured by Optical Waveguide Lightmode Spectroscopy (OWLS) that measure the heparin elution.I have studied which type of polyurethane coated the most heparin. The heparin binding capacity was compared of smooth, porous-free, and porous coating. The porous coating had higher heparin binding capacity than the smooth coating. Furthermore it was studied, if the heparin soaking time is increased in case of the porous coating, the heparin absorption is increased too. It was also concluded, that the increase of the time of the heparin soaking cause increase of heparin absorption.
\end{abstract}

\section{Keywords \\ Coronary stent $\cdot$ polyurethane coating $\cdot$ heparin binding}

\section{Acknowledgement}

This work is connected to the scientific program of the "Development of quality-oriented and harmonized $R+D+I$ strategy and functional model at BME" project. This project is supported by the New Hungary Development Plan (Project ID: TÁMOP4.2.1/B-09/1/KMR-2010-0002).

\section{Liza Pelyhe}

Department of Materials Science and Engineering BME, H-1111 Budapest,Bertalan L street. 7, Hungary

e-mail: liza@t-online.hu

\section{Introduction}

In the treatment of coronary diseases only the surgical intervention were considered to the $90 \mathrm{~s}$, but now the percutaneous radiological interventions have been widespread, sparing patients from a long convalescence time and complications after cardiac surgery [1]. In the 1990s the stents have been developed, which can open the narrowed blood vessels, and can prevent its restenosis [1, 2]. After stent implantation neointima hyperplasia and restenosis frequently has occurred [3]. The first drugeluting stents were appeared in 2002, altering the modern cardiology. The first generation of drug-eluting stents has increased the incidence of thrombosis after implantation, but the studies in 2006-2007 have shown that this occurrence is very limited [2]. The drug-eluting stents reduce the incidence of restenosis [3].Different methods exist to fix the drug to the stent: drug on bare metal, drug mixed with coating, special slot with drug, drug loaded in stent reservoirs [4].

As far back as 1990s it is discovered that the polymer-coated stents and blood vessels can reduce the interaction of damaged vessel area and blood components. 1992 onwards binding to metal and slow release are developed in case of heparin-coated stents [5- $[$ ]. The current researches deal with the development of biodegradable polymer coatings [9, 10]. In some studies sheets were used instead of stents on account of hardly handling of stents too. The material of the sheets was same as stents, 316LVM austenitic stainless steel [11, 12]. The Department of Materials Science and Engineering of BME, the Minvasive Ltd. and the Research Group for Metals Technology of HAS and BME work together on the development of stents for 15 years [13]. This group started the development of drug-eluting stents. One of the initial steps of this research is presented in this article.

\section{Materials and methods}

\subsection{Samples}

Sheets were used for these experiments instead of stents on account of hardly handling of stents. The sheets were $12 \times 3$ $\mathrm{mm}, 316 \mathrm{LVM}$ austenitic stainless steel. Cutting burr was on the surface of the sheets because of the laser cutting. These burr dis- 
appeared after etching. The etching taken 5 minutes to the burr certainly disappeared. Etching liquor and ultrasonic purification machine were used to the etching of sheets.After etching, the samples were cleaned with high purity ethanol through which dries quickly and spotless. After drying the samples were electropolished one at the time to resulted in a smooth surface where the edges became round. Electropolishing stents, given the parameters of the recommendations are based on the size of the surface is applied on the sheets. The optimized parameters for electropolishing were $0,01 \mathrm{~A} / \mathrm{mm}^{2}$ and 90 seconds.

\subsection{Coating preparation}

The coatings were prepared from three, commercially available biocompatible polyurethane from $2 \mathrm{wt} \%$ solution by dipping technique. Three layers were made, and two types of coatings were prepared: smooth, porous-free, and porous. The smooth coatings were prepared at room temperature, the solution were not mixed, slow drying was applied, while the porous coatings were prepared from $4{ }^{\circ} \mathrm{C}$ solution, and were dried in laminar flow.

\subsection{Heparin binding}

The coated sheets were soaked during 24 or 48 hour in $1 \mathrm{mM}$ heparin solution, the control samples were soaked in $10 \mathrm{mM}$ Hepes-1 buffer. After this, the sheets were incubated alone in $420 \mu 110 \mathrm{mM}$ Hepes-1 buffer for 15 , or 120 minutes, or 24 hours. Three samples were made of each type to perform three parallel measurements.

\subsection{Dissolution testing}

The eluting heparin was measured by Optical Waveguide Lightmode Spectroscopy (OWLS).The OWLS technique is based on the measurement of the incident angle dependent photocurrent. A linearly polarized laser beam is incoupled into the waveguiding layer due to a surface grating of the sensor chip. The angle dependence of the photocurrent shows sharp peaks for both the magnetic and electric modes of the light at the right incoupling angles. The position of these peaks depends on the effective refractive index. Changes in refractive index caused by the adsorbed or any covering medium change the position of these peaks [14]. The Fig. 1 indicates ray-optic representation of a coupled and guided wave through waveguide layer of the sensor chip. That is, He-Ne laser $(\mathrm{k}=632.8 \mathrm{~nm})$ is diffracted by a grating at the interface and starts to propagate via the total internal reflection inside waveguide layer. At a well-defined incident angle $(\alpha)$, the phase shift during one internal reflection equals zero (constructive interference) and a guided mode is excited, which generates an evanescent field penetrating into covering medium [15]. The change in refractive index at the surface can be monitored on-line by precise measurement of incoupling angle.

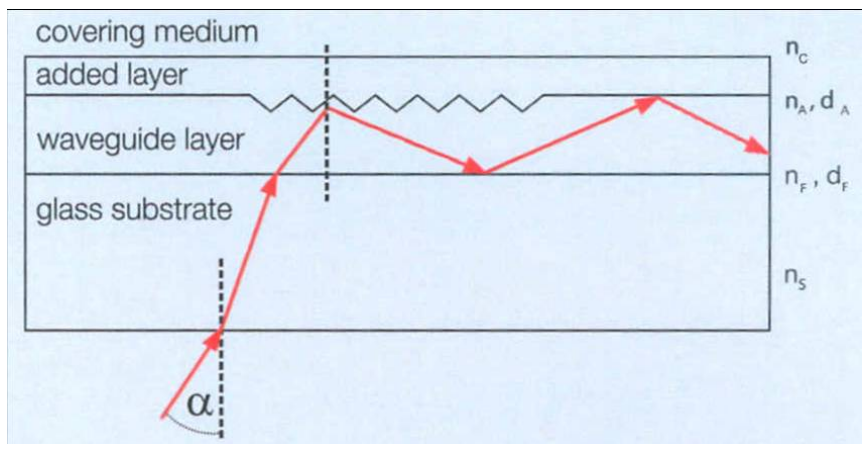

Fig. 1. Ray-optic representation of coupled and guided wave indicated by arrows inside optical grating coupler sensor chip [15].

\section{Results}

Each sheet with heparin gave higher value than the control which was soaked in buffer instead of heparin Fig. 2, Fig. 3. The increase of the incubation time caused the increase of the means of heparin elution. The sample 1 gave the lowest values, and the sample 2 gave the highest values except for the $120 \mathrm{~min}$ utes incubation time from the smooth coating sheets with heparin Fig. 2. Fig. 3.The sample 1 gave the lowest values, and the sample 2 gave the highest values for all three incubation times from the porous coating sheet with heparin Fig. 3 .

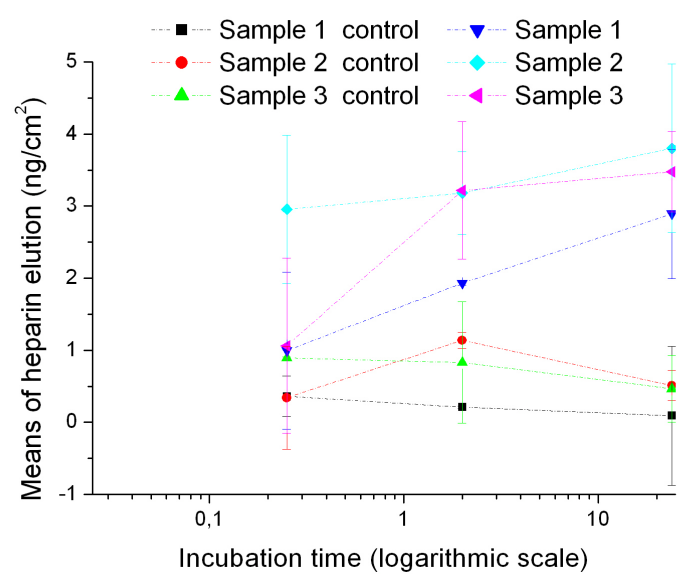

Fig. 2. Means of heparin elution of smooth coated sheets

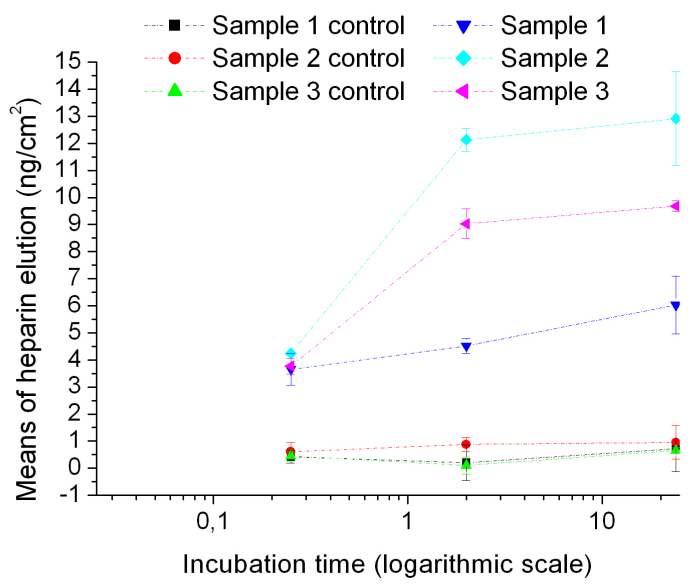

Fig. 3. Means of heparin elution of porous coated sheet 
Compared to the heparin elution of smooth and porous coating, we can see that the values of the porous coating sheets are higher than the values of the smooth coating for each type of polyurethane coatings Fig. 4. The increase of the incubation time caused the increase of the means of heparin elution in case of porous coating sheets with 48 hours soaked time too Fig. 5 The sample 2 gave the highest values between the samples with 48 hours incubation time. Each sheet with 48 hours incubation time gave highest values than sheets with 24 hours incubation time except the sample Fig. 3

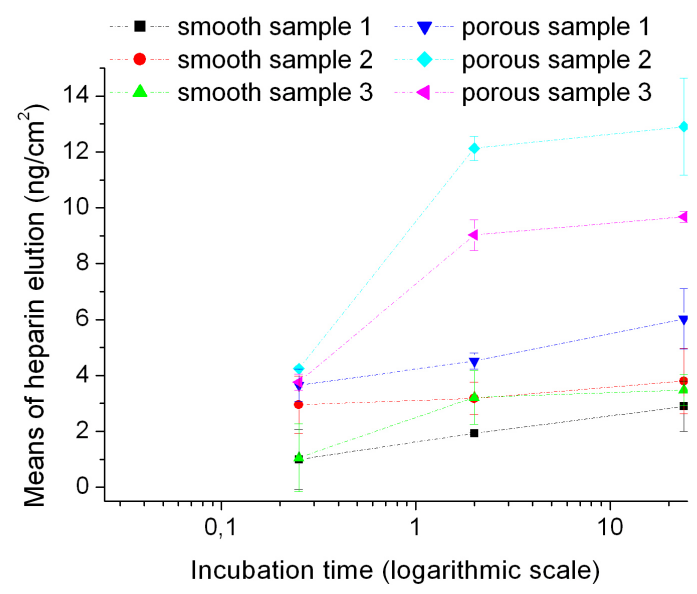

Fig. 4. Means of heparin elution of smooth and porous coating sheets soaked in heparin

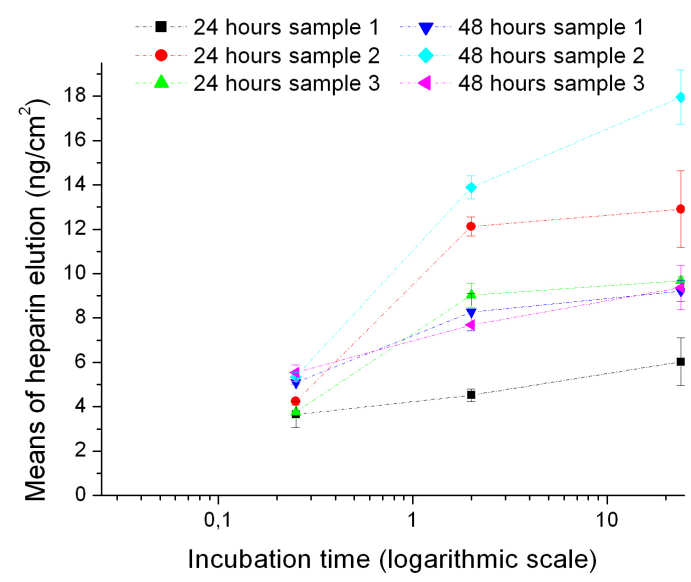

Fig. 5. Means of heparin elution of porous coating sheets soaked 24 or 48 hours in heparin

\section{Discussion}

All of the used polyurethane bound heparin. The sample 2 eluted the most heparin at the smooth and the porous coating sheets too.Compared to the smooth and porous coating, the porous coating eluted more heparin than the smooth coating. The binding surface is increased by pores, so the porous coating can bind more heparin. If the coating sheets were soaked more time, in this case 48 hours instead of 24 hours, then the heparin elution of sheets were increased. The 48 hours were selected to make sure increase the heparin elution. The coated sheet is soaked on and on in heparin, it is bind more heparin, so it can elute more heparin during the elution measure.

\section{Conclusions}

The used polyurethane coatings are suitable for development active coatings, because it was appropriate for heparin binding and elution too. The heparin elution may be increased by application of porous coating or increased of soaked time in heparin.The amount of heparin binding and elution can be controlled by the different surface, and different types of polyurethane coatings.

\section{References}

1 Takács T, Bognár E, Dobránszky J, Az újraszükülést befolyásoló müszaki paraméterek vizsgálata coronariastenteken, Lege Artis Medicinae, 20/3-4(34), (2010), 227-233.

2 Stefanadis C I, Are all drug-eluting stents the same?, Hellenic J Cardiol, 52, (feb) 2011 (jan), 96.

3 Wessely R, New drug-eluting stent concepts, Nat Rev Cardiol, 7, (2010 (april)), 194-203.

4 Bognár E, Ring G, Balázs T, Dobránszky J, Investigation of Drug Eluting Stents, Materials Science Forum, 589, (2008), 361-366.

5 Nathan A, Tissue engineered perivascular endothelial cell implants regulate vascular injury, Proc Natl Acad Sci USA, 92, (1995 (aug)), 8130-8134.

6 Chronos N A F, Robinson K A, Kelly A B, Thromboresistant phosphorylcholine coating for coronary stents, Circulation, 92, (1995), 685.

7 Cox D, Effects of local delivery of heparin and methotrexate on neointimal proliferation in stented porcine coronary arteries, Coron Artery Dis, 3, (1992), 237-248.

8 Serruys P W, Heparin-coated Palmaz-Schatz stents in human coronary arteries. Early outcome of the Benestent-II Pilot Study, Circulation, 93, (1996(feb)), 412-22.

9 Parker T, Davén V, Falotico R, Polymers for drug eluting stents, Curr Pharm Des, 16, (2010), 3978-88.

10 Van Der Giessen W J, Van Beusekom H M, New drug-eluting stents with biodegradable polymers, Minerva Cardioangiol, 59, (2011 Feb), 31-38.

11 Bognár E, Ring G, Marton H Z, Dobránszky J, Ginsztler J, Polyurethane coating on coronary stents, Key Engineering Materials, 345-346, (2007), 1269-1272.

12 Ozsváth P, Bognár E, Sztentbevonatok tapadásának vizsgálata és fejlesztése, Anyagok világa, (2010/1), 1-11.

13 Bognár E, Ring G, Dobránszky J, Koszorúérsztentek anyagvizsgálata, Anyagvizsgálók Lapja, (2004/4), 127-132.

14 Szendrö I, Combination of the optical waveguide lightmode spectroscopy method with electrochemical measurements, Thin Solid Films, 516, (2008), 8165-8169.

15 Vörös J, Ramsden J J, Csúcs G, Optical grating coupler biosensors, Biomaterials, 17, (2002 Sept,23), 3699-710. 